\title{
A Multi-Objective Optimization Model for the Life-cycle Cost Analysis and Retrofitting Planning of Buildings
}

\author{
Bo WANG, Xiaohua XIA, Jiangfeng ZHANG \\ Department of Electrical, Electronic and Computer Engineering, University of Pretoria, Pretoria 0002, South Africa
}

\begin{abstract}
The building sector contributes a large proportion of the world's total final energy consumption. As a result, considerable attention has been paid to energy efficiency in the building sector. At the current stage, building retrofitting is the most feasible and cost-effective method to improve building energy efficiency. This paper presents a multi-objective optimization model for life-cycle cost analysis and retrofitting planning of buildings. A Net Present Value (NPV) based economic analysis taking life-cycle cost into account is introduced to formulate the objective functions. In addition, a combination of multiple alternative measures for each retrofitting intervention is considered in determining the optimal solution. The presented model aims at maximizing both energy savings and economic benefits during a selected time frame. It allows decision makers to make best use of the available budget. A Differential Evolution (DE) algorithm is proposed to solve this optimization problem. The result of the case study illustrates the effectiveness of the multi-objective optimization model to support the planning of energy-efficient and cost-effective building retrofitting projects.
\end{abstract}

Keywords: Building retrofitting, Multi-objective optimization, Life-cycle cost, Multiple retrofitting measures

\section{Introduction}

The building sector is nowadays drawing considerable attention in the energy area, being responsible for about $40 \%$ of the total energy consumption in the European Union (EU) and $32 \%$ in the world [1]. The practice of green buildings can reduce the growth of future energy demands. However, improving the energy efficiency in existing buildings is not similar to that in a brand new green building. Building retrofitting is currently the most feasible method to reduce the present energy demands in existing buildings ${ }^{1}$.

During the building retrofitting, Energy Conservation Measures (ECMs) are taken on the current facilities. The development of technologies allows more and more available ECMs to improve the energy performance, whereas the selection of proper measures needs to satisfy several different requirements. Decision makers should take energy, economic, social and other factors into account to strike the best balance between stakeholders' and occupants' requirements [2]. The obtained optimal solution is usually a trade-off between these energy and non-energy related factors. Therefore a key problem of building retrofitting is the identification of the proper measures for the project using different criteria based on specific requirements.

Over the last decade, the Multi-Criteria (MC) model has often been used to evaluate a building retrofitting project. The criteria mainly focus on the energy efficiency, the capital cost and other comfort factors, such as the usable space for the occupants in the building [3], the air quality and the thermal comfort [4]. Some MC-based approaches for the evaluation of retrofitting projects can be found from $[5,6,7,8]$. During

\footnotetext{
${ }^{1}$ A Guide to Energy Management in Public Buildings, 2008, http://old.gbcsa.org.za/system/data/uploads/resource/ 101_res.pdf
} 
the design phase of a retrofitting project, $\mathrm{MC}$ are also adopted. Energy saving and capital cost are the most considered criteria for optimal building retrofitting planning [9, 10]. As the requirements within these criteria are often contradictory, the planning process is essentially a multi-objective optimization problem subject to several constraints.

According to a recent review [11], there is clear growth in the popularity of multi-objective optimization for sustainable building design. Recent research [12] especially discusses a multi-objective optimization model for building retrofitting investment decision. The objectives of the model are to maximize the energy savings and minimize the payback period for the given initial investment. By using the model in [12], a costeffective retrofitting plan with a budget constraint can be obtained. However, in [12], the optimal solution is restricted only to a single preselected retrofitting measure per type of intervention. In practical projects, more alternatives can be provided for each type of intervention. The decision maker has to select the proper measures, even a combination of several measures from all available options for the same intervention. Such a selection is difficult to make prior to the multi-objective optimization. A more feasible method is to simultaneously consider all available alternatives during the optimization. The selection of proper measures thus becomes a part of the optimization.

When evaluating several alternatives, one must not only consider the initial cost of an alternative, as one alternative could appear cost-effective at the installation stage but more expensive to maintain during the operation than other alternatives. Such alternative would in fact not be a cost-effective option over the long term. To evaluate the long-term cost-effectiveness of building retrofitting investments, Life-Cycle Cost Analysis (LCCA) should be applied. LCCA is an advanced technique especially for assessing the total cost of facility ownership. The Life-Cycle Cost (LCC) is associated with the estimation of future cash flow. The LCC of an asset is defined as the total cost throughout its life including planning, design, acquisition, support and any other costs directly attributable to owning or using the asset ${ }^{2}$. For the building retrofitting investments, LCCA, a widely used technique for building retrofitting, can be applied to estimate the overall cost of the alternatives during the life-cycle of the building and evaluate the cost-effectiveness. Kaynakli [13] used LCCA to determine the optimal thickness of the insulation material in a building envelope for best cost-effectiveness. Menassa [14] presented a method to determine the investment of building retrofitting projects by taking into account different uncertainties associated with life-cycle cost and perceived benefits of this investment.

The Simple Payback Period (SPP) was chosen to assess the economic viability in [12]. A variety of typical economic analysis methods can be used to evaluate the cost-effectiveness of building retrofitting investments, such as Net Present Value (NPV), Internal Rate of Return (IRR), Overall Rate of Return (ORR), BenefitCost Ratio (BCR), Discounted Payback Period (DPP) and SPP [15, 16]. When the future cash flow is taken into account, NPV is identified as the most widely used technique for optimal building energy assessment [17]. The NPV method, rather than the other economic analysis methods, translates the future cash flow into the present value of money, provides an explicit method to evaluate the overall value of a project. If the NPV of a prospective project within a chosen time frame is non-negative, the project is considered profitable. Verbeeck and Hens [18] as well as Petersen and Svendsen [19] used the NPV method to compare the economic viability of different retrofitting measures.

This paper builds on and extends the study of [12] by presenting a multi-objective optimization model with life-cycle cost analysis for building retrofitting planning. The optimization model involves both selecting proper retrofitting measures from a range of available alternatives per type of intervention and determining the quantities of retrofitted facilities using the chosen retrofitting measures. The model aims at minimizing energy consumption, reducing the payback period and maximizing economic benefits with the lowest possible life-cycle cost. The payback period is defined as the earliest possible time after which the NPV of this project

\footnotetext{
${ }^{2}$ NSW Treasury, Life Cycle Costing Guideline, http://www.treasury.nsw.gov.au/_data/assets/pdf_file/0005/5099/ life_cycle_costings.pdf
} 
remains non-negative. The economic viability is assessed by the NPV method. Life-cycle cost indicates the economic sustainability of the project and minimal life-cycle cost is emphasized in the model to guarantee long-term cost-effectiveness.

The presented model considers combinations of multiple alternative retrofitting measures in a building. There are many possible combinations, and the evaluation of alternatives often involves non-linear objective functions, as shown in $[9,10,12]$. With the development of computational powers and algorithms, it is possible to address problems that were previously infeasible [11]. The Evolutionary Algorithm (EA), a kind of generic population-based meta-heuristic optimization algorithm, is generally applied to address building energy optimization problems. As a typical EA, Genetic Algorithms (GAs) are widely used in optimal building retrofitting studies, such as [20] and [12]. However, when using GAs to solve a new optimization problem, the encoding becomes difficult and the convergence speed is slow. As one of the improvements of the classical EAs, Differential Evolution (DE) algorithms are simple and efficient heuristic methods first proposed by [21]. According to [21] and [22], DE generally outperforms GAs and many other algorithms on many numerical benchmark problems, including unimodal as well as multimodal functions, functions with correlated and uncorrelated variables, and a single problem with plateaus. Comparing to the other EAs, DE is robust, converges faster, and easy to implement. Consequently, a DE algorithm is adopted to solve the optimization problem presented in this paper. As a case study, a practical building retrofitting project is used to test and verify the feasibility and advantages of the proposed approach.

The remainder of this paper consists of four sections. Section 2 gives the formulation of the multi-objective optimization model. Section 3 introduces the DE algorithm to solve the optimization problem. Section 4 provides results and analysis. Section 5 draws conclusions and discusses future research.

\section{Multi-objective Optimization Model}

\subsection{Decision variables}

A building retrofitting plan consists of a set of retrofitting actions, which represents what and how retrofitting measures are implemented. The retrofitting action is characterized by three components: the existing facility to be retrofitted, the alternative interventions of new technological interventions and the quantities of items corresponding to the chosen interventions, as demonstrated in Table 1.

\begin{tabular}{c|c|c}
\multicolumn{2}{c}{ Table 1: A sample retrofitting plan } \\
\hline Facilities & Alternatives & Quantities \\
\hline \multirow{3}{*}{ Lighting } & Lighting Intervention 1 & 20 \\
& Lighting Intervention 2 & 0 \\
& Lighting Intervention 3 & 35 \\
\hline \multirow{2}{*}{ Geyser } & Geyser Intervention 1 & 25 \\
\hline \multirow{2}{*}{ Air-Con } & Air-Con Intervention 1 & 0 \\
& Air-Con Intervention 2 & 30 \\
\hline
\end{tabular}

Assume that there are $I$ types of facilities to be retrofitted, each corresponds to $J_{i}$ types of alternative interventions. Let $x_{i}^{j}$ denote the number of selected items from the $i$-th type of facility with the $j$-th alternative intervention, namely alternative intervention $(i, j)$. For $i=1,2, \ldots, I$, let $X_{i}=\left(x_{i}^{1}, x_{i}^{2}, \ldots, x_{i}^{J_{i}}\right)$, and $X=\left(X_{1}, X_{2}, \ldots, X_{I}\right) . X$ is the decision variable which characterizes a retrofitting plan.

\subsection{Multi-objectives formulation}

Three objective functions are involved in the model. They are formulated as equations (1)-(3):

$$
\begin{gathered}
f_{1}(X)=E S, \\
f_{2}(X)=N P V,
\end{gathered}
$$




$$
f_{3}(X)=T_{p}
$$

and there are the following constraints:

$$
\left\{\begin{array}{c}
E S \geq \alpha, \\
T_{p} \leq T^{\prime}, \\
I_{0} \leq \beta,
\end{array}\right.
$$

where $E S$ is the total amount of energy savings during a time period $[0, T]$, where 0 is the initial time point. To reduce the influence of accumulated errors over time, $T$ is determined as the length of a specific time period in our case, namely evaluation period. $T$ is not necessarily the whole lifetime of the building. The cost-effectiveness and energy-efficiency of a retrofitting project are evaluated during the evaluation period. $T_{p}$ is the discounted payback period. For simplicity, $T_{p}$ is defined here as the time point after which the NPV becomes and stays non-negative.

In the constraints, $\alpha$ is the targeted amount of energy savings, which is usually a percentage of the energy consumption of the retrofitted building. $T^{\prime}$ is the expected payback period. $\beta$ is the budget limit of the retrofitting project. $I_{0}$ represents the initial cost of the project, which includes the cost of purchasing items and human labor for installation. Another form of constraints (4) can be written as:

$$
\left\{\begin{array}{l}
E S \geq \alpha, \\
T_{p} \leq T^{\prime} \\
I_{\text {all }} \leq \beta^{\prime}
\end{array}\right.
$$

where the $\beta^{\prime}$ is the budget limit for overall cost during the evaluation period. This new budget is represented by $\beta^{\prime}$. This scenario implies that there is a limit for the overall cost of the project during the evaluation period. The impact of implementing different constraints will be discussed in the result and analysis section.

The objectives of this model are maximizing objective function $f_{1}(X)$ and $f_{2}(X)$, while minimizing $f_{3}(X)$. Maximizing $f_{1}(X)$ is to maximize the energy saving. Maximizing $f_{2}(X)$ and minimizing $f_{3}(X)$ will guarantee the economic benefits of the project. Implementing the three objectives allows a retrofitting plan that strikes a balance between the total profit of the project and the earlier payback of the investment.

\subsection{Model analysis}

The parameters in the objective functions (1)-(3) are calculated by the following equations:

$$
\begin{gathered}
E S=\sum_{t=1}^{T} \sum_{i=1}^{I} \sum_{j=1}^{J_{i}} a_{i}^{j}(t) x_{i}^{j}(t), \\
N P V=\sum_{t=1}^{T} \frac{B(t)-C_{m}(t)}{(1+d)^{t}}-I_{0},
\end{gathered}
$$

in which

$$
\begin{gathered}
I_{0}=\sum_{i=1}^{I} \sum_{j=1}^{J_{i}} b_{i}^{j} x_{i}^{j}, \\
B(t)=\sum_{i=1}^{I} \sum_{j=1}^{J_{i}} a_{i}^{j}(t) x_{i}^{j}(t) p(t), \\
C_{m}(t)=\sum_{i=1}^{I} \sum_{j=1}^{J_{i}} u_{i}^{j}(t) m_{i}^{j}(t) .
\end{gathered}
$$

In these equations, $a_{i}^{j}(t)$ represents the energy saving at time point $t$ of an item from the $i$-th type of facility with the $j$-th alternative measure. $a_{i}^{j}(t)$ is usually a constant, whereas it is considered dynamic in some 
cases due to the fatigue of the facilities. In equation $(7), B(t)$ represents the profit of the retrofitting project at time point $t, C_{m}(t)$ represents the maintenance cost within the whole project at time $t$. In our present model, the maintenance cost mainly takes the cost of replacing or repairing the interventions into account. $d$ is the discount rate for NPV calculation. $I_{0}$ is the overall initial capital cost of the project, and $b_{i}^{j}$ is the cost of installing a single item with the alternative intervention $(i, j)$. In equations $(9)$ and $(10), p(t)$ is the electricity price at time $t$ and $m_{i}^{j}(t)$ is the maintenance cost of an item with the alternative intervention $(i, j)$ at time $t$. Usually the estimation of such prices takes into account the inflation. $u_{i}^{j}(t)$ represents the number of maintenances that took place in this population at the previous time point, which can be considered as the control input of the maintenance problem.

$x_{i}^{j}(t)$ represents the number of available items at time $t$. Therefore, $x_{i}^{j}(0)=x_{i}^{j}$. The influence of facilities failures is taken into account in equations (6)-(10). The "failures" in the model refer to the problems that make the facilities no longer available to the occupants of the building, for example, a faulty, flickering light bulb, mechanical problems of the condenser or compressor of an air conditioner which prevent it from working, etc. Items with such problems are considered as failed items which do not contribute to energy savings and the corresponding profit. Maintenance of such items is the main source of the future cash outflow. There could also be some electrical and mechanical problems which do not stop the items from working, for example, the fatigue of a bulb or the refrigerant in an air conditioner needs to recharge. The performance of the items will deteriorate due to these problems. However, such deterioration is not significant compared to the estimation value of energy savings and the influence of the failed items. Thus such issues of "degradation of service level" are not taken into account in the current model. The number of the available items is estimated by the following equation:

$$
x_{i}^{j}(t+1)=D_{i}^{j}\left(x_{i}^{j}(t)\right)+u_{i}^{j}(t),
$$

where $D_{i}^{j}(\cdot)$ represents the decay of the population of items with alternative intervention $(i, j)$. According to the research on facility population decay [23], such decay is considered as a first-order Markov process, which means the population size after decay only relates to the population size prior to the decay. As the population decay mainly results from the failures of the items, the decay rate of a population with alternative intervention $(i, j)$ can be characterized by the failure rate of the corresponding intervention. Two models according to the existing research are adopted for the present model to estimate the population decay:

$$
\begin{gathered}
D_{i}^{j}\left(x_{i}^{j}(t)\right)=b_{i}^{j} c_{i}^{j} x_{i}^{j}(t)^{2} / x_{i}^{j}-b_{i}^{j} x_{i}^{j}(t)+x_{i}^{j}(t), \\
D_{i}^{j}\left(x_{i}^{j}(t)\right)=x_{i}^{j}(t) e^{-k_{i}^{j}},
\end{gathered}
$$

where the coefficients $b, c, k$ are estimated by the Mean Time To Failure (MTTF) for the non-repairable product and Mean Time Between Failures (MTBF) for repairable product. Equation (12) is taken from [23]. It describes the decay of the population of lamps, showerheads or motion sensors. Such facilities are considered non-repairable in the model, whose MTTF is the rated lifetime, i.e., the length of the life cycle of the item. Let $L_{i}^{j}$ denote the rated lifetime, the general form of time-domain decay model $X_{i}^{j}(t)=\left(c_{i}^{j}+e^{b_{i}^{j} t-L_{i}^{j}}\right)^{-1}$ can be found in [23]. $b_{i}^{j}$ and $c_{i}^{j}$ can be identified from experimental data, whereas when $L_{i}^{j}$ is known, they can also be obtained by solving out the following equations:

$$
\left\{\begin{array}{c}
X_{i}^{j}(0)=1, \\
X_{i}^{j}\left(L_{i}^{j}\right)=0.5 .
\end{array}\right.
$$

Equation (13) describes the decay of the population of air conditioners, chillers or heat pumps that are considered repairable products. For such a facility, the length of its life cycle is usually several times longer than the MTBF. According to the reliability bathtub curve [24], the failure rate of the population is an approximately low constant before the end of the lifetime. Therefore an exponential decay model is adopted from [24] in equation (13). Let $\theta_{i}^{j}$ denote the MTBF of the facility, then $k_{i}^{j}$ is obtained from the following equation:

$$
k_{i}^{j}=\left(\theta_{i}^{j}\right)^{-1} .
$$


For each $(i, j)$, the initial population size is $x_{i}^{j}$, as the number of items to be installed at the initial time. As described in equation (11), the new population is the summation of the survival of the previous population and the control input $u_{i}^{j}(t) . u_{i}^{j}(t)$ at each time point $t$ is decided according to the maintenance plan, which varies in different projects. Equation (10) calculates the maintenance cost, in which the unit maintenance $\operatorname{cost} m_{i}^{j}(t)$ is the price to maintain an item. For the non-repairable product, maintenance is to replace the failed items, $m_{i}^{j}(t)$ is the price of the item at time point $t$. For the repairable product, maintenance refers to the repairs, $m_{i}^{j}(t)$ is often a percentage of the item price [25].

\subsection{The weighted sum method for multi-objective optimization}

The multi-objective optimization model (1)-(10) can be solved by the weighted sum method. According to the analysis in [26], the weighted sum method provides a basic and easy-to-use approach that gives an acceptable approximation of one's preference function when the preference information is not too complex. In this model, the solution is a trade-off between energy performance and the investment. Thus the optimization problem is translated into the minimization of a fitness function, which is the weighted sum of objective functions associated with stationary penalty functions representing the constraints, given by equation (16):

$$
F(x)=-\lambda_{1} f_{1}(x)-\lambda_{2} f_{2}(x)+\lambda_{3} f_{3}(x)+\omega \sum_{k=1}^{3} \max \left(0, P_{k}\right),
$$

where $\lambda_{1}, \lambda_{2}, \lambda_{3}$ are a set of positive constant weights. During calculation, the objective functions are adjusted such that they have similar value ranges. $\omega$ is a positive constant associated with the penalties. $P_{k}$ is the penalty function representing the constraints for this problem, and is defined as follows:

$$
P_{k}=\left\{\begin{array}{cc}
\alpha-E S, & k=1, \\
T_{p}-T^{\prime}, & k=2, \\
I_{0}-\beta, & k=3
\end{array}\right.
$$

As given in constraint (5), there is another form of penalty functions in which the budget limit is for the overall cost of the project:

$$
P_{k}= \begin{cases}\alpha-E S, & k=1, \\ T_{p}-T^{\prime}, & k=2, \\ I_{\text {all }}-\beta^{\prime}, & k=3 .\end{cases}
$$

\section{Solution by DE Algorithm}

The basic operation of DE algorithm follows the general procedure of an evolutionary algorithm. There are three main steps in a DE algorithm: Mutation, Crossover and Selection. The main difference between GA and DE is that a differential vector generated from the current population is used to mutate the corresponding parent. Then, a binomial crossover operation is applied to the parent vector and the mutation vector. The result, namely child vector, is compared with its parent, and the winner with better fitness value is selected to form the population of the next generation [27].

The pseudocode of the DE algorithm is presented in Table 2. In this method, let $D$ denote the dimension of the problem. $G$ refers to the maximum step of iteration. $N P$ represents the population size. The $C R$ and $F$ are the crossover probability, and the mutation coefficient. $X_{b e s t, g}^{p}$ is chosen from the $10 \%$ best vectors of the current population. $X_{r 1 . g}-X_{r 2 . g}$ is a differential vector for the mutation operation, where $X_{r 1 . g}, X_{r 2 . g}$ are randomly selected from the current population. The mutation vector $V_{i, g}$ and the child vector $U_{i, g}$ are accordingly generated. Fitness function $F(\cdot)$ refers to equation (16). As introduced above, DE algorithm is a simple and efficient heuristic for global optimization. Consequently, DE finds the optimum in almost every run [22]. For our presented optimization model, it is difficult to determine whether the optimization result is globally optimal. However, the heuristic of DE provides the ability of escaping from local plateau. 
Table 2: Pseudocode of DE algorithm

\begin{tabular}{|c|c|}
\hline line\# & Procedure of the DE based method \\
\hline 01 & Begin \\
\hline 02 & Set $C R=0.5 ; F=0.5 ; A=\varnothing$; \\
\hline 03 & Create a random initial population $\left\{X_{i, 0} \mid i=1,2, \ldots, N P\right\}$; \\
\hline 04 & For $g=1$ to $G$ \\
\hline 05 & For $i=1$ to $N P$ \\
\hline 06 & Randomly choose $X_{r 1, g} \neq X_{i, g}$ from current population $\mathbf{P}$ \\
\hline 07 & Randomly choose $X_{r 2, g} \neq X_{i, g}$ from current population $\mathbf{P}$ \\
\hline 08 & Randomly choose $X_{\text {best }, g}^{p}$ as one of the $10 \%$ best vectors from $\mathbf{P}$; \\
\hline 09 & $V_{i . g}=X_{i . g}+F \cdot\left(X_{\text {best }, g}^{p}-X_{i . g}\right)+F \cdot\left(X_{r 1 . g}-X_{r 2 . g}\right)$ \\
\hline 10 & Generate $j_{\text {rand }}=\operatorname{randint}(1, D) ;$ \\
\hline 11 & For $j=1$ to $D$ \\
\hline 12 & IF $j=j_{\text {rand }}$ or $\operatorname{rand}(0,1)<C R$ \\
\hline 13 & $U_{j, i, g}=U_{j, i, g}$ \\
\hline 14 & ELSE \\
\hline 15 & $U_{j, i, g}=X_{j, i, g}$ \\
\hline 16 & END IF \\
\hline 17 & END FOR \\
\hline 18 & IF $F\left(U_{i, g}\right) \leq F\left(X_{i, g}\right)$ \\
\hline 19 & $X_{i, g+1}=U_{i, g}$ \\
\hline 20 & ELSE \\
\hline 21 & $X_{i, g+1}=X_{i, g}$ \\
\hline 22 & END IF \\
\hline 23 & END FOR \\
\hline 23 & END FOR \\
\hline 24 & END \\
\hline
\end{tabular}

Generally, the solution is considered optimal when convergence is achieved and sufficient iteration number is reached.

The parameters of DE algorithm are tuned in advance and kept fixed during the calculation. NP is usually about 4 times of the value of $D$ to ensure the population diversity and convergence speed. The key parameters are $C R$ and $F$. The value of $C R$ represents the trust in the mutation result. Larger $F$ is recommended because it is helpful to increase the diversity of the population [28]. $C R$ and $F$ are chosen to be 0.5 in our case.

\section{Results and Analysis}

\subsection{Case study}

A retrofitting project similar to the case study in [12] is investigated. The difference is that multiple alternatives for each intervention as well as the life-cycle cost information are incorporated. In this case study, 12 types of energy efficiency potential facilities are considered and optimized in the building, including lighting facilities, heat pumps, chillers, control systems and other devices. Each facility type has 2-5 alternative interventions. The content of the input data is shown in Table 3, including information on the existing facilities and corresponding alternative measures. The information on these 12 types of facilities and their alternative interventions are also given in Table 3. The Maximum Possible Quantity column regulates how many items from a specific type of facility that can be retrofitted. The overall number of retrofitted items for a specific intervention cannot exceed its maximum possible quantity. The Unit Cost with unit USD $(\$)$ here is the cost of purchasing and installing one such item; Energy Savings with unit kWh is the estimation of the average annual energy saving from implementing the selected retrofitting measure to one such item; Unit Cost Saving is the estimation of financial benefit from the energy saving. The maintenance cost and the MTTF/MTBF are recorded within Maintenance Cost and $M T T F / M T B F$ respectively. For simplicity, the unit of MTTF/MTBF is translated into months rather than hours. The coefficients of the decay models for each intervention are shown in Table 4. As mentioned in the previous section, there are non-repairable 
Table 3: Detailed information on existing and proposed alternative facilities

\begin{tabular}{|c|c|c|c|c|c|c|c|}
\hline Existing Facilities & $\begin{array}{l}\text { Maximum } \\
\text { possible } \\
\text { quantity }\end{array}$ & Proposed alternatives & $\begin{array}{l}\text { Unit } \\
\text { Cost } \\
(\$)\end{array}$ & $\begin{array}{l}\text { Energy } \\
\text { Savings } \\
(\mathrm{kWh})\end{array}$ & $\begin{array}{l}\text { Unit Cost } \\
\text { Savings } \\
(\$)\end{array}$ & $\begin{array}{l}\text { Main- } \\
\text { tenance } \\
\text { Cost }(\$)\end{array}$ & $\begin{array}{l}\text { MTTF } \\
\text { /MTBF }\end{array}$ \\
\hline No sensors installed & 202 & $\begin{array}{l}\text { Motion sensor type1 } \\
\text { Motion sensor type2 }\end{array}$ & $\begin{array}{l}196 \\
150.28\end{array}$ & $\begin{array}{l}1141 \\
1240\end{array}$ & $\begin{array}{l}155.02 \\
168.47\end{array}$ & $\begin{array}{l}196 \\
150.28\end{array}$ & $\begin{array}{l}36 \\
41\end{array}$ \\
\hline 50W downlight I & 537 & $\begin{array}{l}\text { energy saver globe type } 1 \\
\text { energy saver globe type } 2 \\
\text { energy saver globe type } 3 \\
\text { energy saver globe type } 4\end{array}$ & $\begin{array}{l}16.36 \\
16.93 \\
20.19 \\
18.95\end{array}$ & $\begin{array}{l}208 \\
223 \\
195 \\
220\end{array}$ & $\begin{array}{l}10.65 \\
11.42 \\
9.98 \\
11.26\end{array}$ & $\begin{array}{l}16.36 \\
16.93 \\
20.19 \\
18.95\end{array}$ & $\begin{array}{l}40 \\
35 \\
42 \\
40\end{array}$ \\
\hline 50W downlight II & 145 & $\begin{array}{l}35 \mathrm{~W} \text { new lamp ECG type1 } \\
35 \mathrm{~W} \text { new lamp ECG type } 2 \\
35 \mathrm{~W} \text { new lamp ECG type3 }\end{array}$ & $\begin{array}{l}14.19 \\
15.17 \\
14.25\end{array}$ & $\begin{array}{l}102 \\
116 \\
107\end{array}$ & $\begin{array}{l}5.2 \\
5.91 \\
5.45\end{array}$ & $\begin{array}{l}14.19 \\
15.17 \\
14.25\end{array}$ & $\begin{array}{l}40 \\
45 \\
43\end{array}$ \\
\hline $18 \mathrm{~W}$ recessed fitting I & 270 & $\begin{array}{l}18 \mathrm{~W} \text { retrofitting ECG type1 } \\
18 \mathrm{~W} \text { retrofitting ECG type2 } \\
18 \mathrm{~W} \text { retrofitting ECG type3 }\end{array}$ & $\begin{array}{l}11.72 \\
11.11 \\
9.47\end{array}$ & $\begin{array}{l}21 \\
20 \\
25\end{array}$ & $\begin{array}{l}1.07 \\
1.02 \\
1.27\end{array}$ & $\begin{array}{l}11.72 \\
11.11 \\
9.47\end{array}$ & $\begin{array}{l}38 \\
31 \\
33\end{array}$ \\
\hline $54 \mathrm{~W}$ recessed fitting II & 1271 & $\begin{array}{l}36 \mathrm{~W} \text { triphosphor tubes type } 1 \\
36 \mathrm{~W} \text { triphosphor tubes type } 2 \\
36 \mathrm{~W} \text { triphosphor tubes type } 3 \\
36 \mathrm{~W} \text { triphosphor tubes type } 4 \\
36 \mathrm{~W} \text { triphosphor tubes type } 5\end{array}$ & $\begin{array}{l}65.67 \\
78.09 \\
61.54 \\
60.77 \\
65.29\end{array}$ & $\begin{array}{l}232 \\
186 \\
262 \\
260 \\
199\end{array}$ & $\begin{array}{l}11.88 \\
9.52 \\
13.42 \\
13.31 \\
10.19\end{array}$ & $\begin{array}{l}65.67 \\
78.09 \\
61.54 \\
60.77 \\
65.29\end{array}$ & $\begin{array}{l}39 \\
37 \\
38 \\
34 \\
38\end{array}$ \\
\hline Old chillers & 4 & $\begin{array}{l}\text { New chillers type } 1 \\
\text { New chillers type } 2\end{array}$ & $\begin{array}{l}147125 \\
170590.31\end{array}$ & $\begin{array}{l}25392 \\
23539\end{array}$ & $\begin{array}{l}13775.88 \\
12770.57\end{array}$ & $\begin{array}{l}14712.5 \\
17059.03\end{array}$ & $\begin{array}{l}24 \\
27\end{array}$ \\
\hline Electric geyser & 9 & $\begin{array}{l}3 \mathrm{~kW} \text { heat-pumps type } 1 \\
3 \mathrm{~kW} \text { heat-pumps type } 2 \\
3 \mathrm{~kW} \text { heat-pumps type } 3\end{array}$ & $\begin{array}{l}1250 \\
1299.22 \\
1544.88\end{array}$ & $\begin{array}{l}10989 \\
11166 \\
12074\end{array}$ & $\begin{array}{l}794.44 \\
807.24 \\
872.88\end{array}$ & $\begin{array}{l}125 \\
129.92 \\
154.49\end{array}$ & $\begin{array}{l}24 \\
27 \\
22\end{array}$ \\
\hline Electric geyser & 3 & $\begin{array}{l}22 \mathrm{~kW} \text { heat-pumps type } 1 \\
22 \mathrm{~kW} \text { heat-pumps type } 2 \\
22 \mathrm{~kW} \text { heat-pumps type } 3\end{array}$ & $\begin{array}{l}13750 \\
13757.97 \\
12600.01\end{array}$ & $\begin{array}{l}1006 \\
875 \\
1152\end{array}$ & $\begin{array}{l}1854.13 \\
1612.69 \\
2123.22\end{array}$ & $\begin{array}{l}1375 \\
1375.79 \\
1260.01\end{array}$ & $\begin{array}{l}24 \\
23 \\
27\end{array}$ \\
\hline Electric geyser & 94 & $\begin{array}{l}9 \mathrm{~kW} \text { heat-pumps type } 1 \\
9 \mathrm{~kW} \text { heat-pumps type } 2 \\
9 \mathrm{~kW} \text { heat-pumps type } 3\end{array}$ & $\begin{array}{l}1250 \\
1355.36 \\
954.95\end{array}$ & $\begin{array}{l}10989 \\
12447 \\
9019\end{array}$ & $\begin{array}{l}72.74 \\
82.39 \\
59.7\end{array}$ & $\begin{array}{l}125 \\
135.54 \\
95.5\end{array}$ & $\begin{array}{l}24 \\
26 \\
26\end{array}$ \\
\hline High-flow showerheads & 360 & $\begin{array}{l}\text { Low-flow showerheads type } 1 \\
\text { Low-flow showerheads type } 2\end{array}$ & $\begin{array}{l}11.25 \\
10.54\end{array}$ & $\begin{array}{l}278 \\
254\end{array}$ & $\begin{array}{l}18.61 \\
17\end{array}$ & $\begin{array}{l}11.25 \\
10.54\end{array}$ & $\begin{array}{l}65 \\
58\end{array}$ \\
\hline No heater wraps & 107 & $\begin{array}{l}\text { Heater wraps type1 } \\
\text { Heater wraps type } 2 \\
\text { Heater wraps type3 }\end{array}$ & $\begin{array}{l}21 \\
24.32 \\
22.36\end{array}$ & $\begin{array}{l}273 \\
326 \\
243\end{array}$ & $\begin{array}{l}21 \\
25.08 \\
18.69\end{array}$ & $\begin{array}{l}21 \\
24.32 \\
22.36\end{array}$ & $\begin{array}{l}51 \\
48 \\
60\end{array}$ \\
\hline No thermal traps & 107 & $\begin{array}{l}\text { Thermal traps type1 } \\
\text { Thermal traps type } 2\end{array}$ & $\begin{array}{l}8 \\
9.13\end{array}$ & $\begin{array}{l}380 \\
350\end{array}$ & $\begin{array}{l}8 \\
7.37\end{array}$ & $\begin{array}{l}8 \\
9.13\end{array}$ & $\begin{array}{l}67 \\
49\end{array}$ \\
\hline
\end{tabular}

items which applies the decay model from equation (12), and repairable items which applies the decay model from equation (13). The coefficients $k_{i}^{j}, b_{i}^{j}$ and $c_{i}^{j}$ for different interventions are given respectively in the three columns. These coefficients are calculated according to equation (14) and (15).

Some parameters in the optimization model are selected according to the specifics of the project. In this case study, the evaluation period is 10 years. The targeted energy saving amount is $10 \%$ of the energy baseline. The baseline energy consumption per year is known as $5,870,911 \mathrm{kWh}$ in this project, thus the energy baseline is $58,709,110 \mathrm{kWh}$, i.e., the overall baseline energy consumption during the evaluation period. Baseline adjustment is not considered here, as this baseline mainly provides a targeted saving value. The budget limit is shown in Table 5. There are 8 scenarios in Table 5. The first 4 scenarios $A, B, C, D$ adopt budget constraint from equation (17) while the rest scenarios $E, F, G, H$ adopt the budget constraint from equation (18). Thus the range of the budget amounts is much larger in the last 4 scenarios. The discount rate in NPV calculation is $9 \%$, which is recommended in South Africa [12]. For simplicity, the interest rate of the electricity price and the cost savings is considered constant during the evaluation period, which is 7.1\% according to the 2013 Eskom notification ${ }^{3}$. The inflation of the maintenance costs is not considered in this case study. The maintenance plan is decided by the owner of the building. In practise the failed items are maintained together for convenience. Such maintenance usually takes place once every year or two years. For the case study, $u_{i}^{j}(t)$ applies the following maintenance strategy from a practical building

\footnotetext{
${ }^{3} \mathrm{http}$ ///www.eskom.co.za/c/article/1772/notification-of-20132014-tariff-increase/
} 
Table 4: Coefficients of the decay models

\begin{tabular}{|c|c|c|c|c|}
\hline Existing Facilities & Proposed alternatives & $k_{i}^{j}$ & $y_{i}^{j}$ & $z_{i}^{j}$ \\
\hline No sensors installed & Motion sensor type1 & & 1.2895 & $\begin{array}{l}i \\
0.9502 \\
0.9672\end{array}$ \\
\hline 50W downlight I & $\begin{array}{l}\text { energy saver globe type } 1 \\
\text { energy saver globe type } 2 \\
\text { energy saver globe type } 3 \\
\text { energy saver globe type } 4\end{array}$ & & $\begin{array}{l}1.2587 \\
1.2984 \\
1.2458 \\
1.2587\end{array}$ & $\begin{array}{l}0.9643 \\
0.9459 \\
0.9698 \\
0.9643\end{array}$ \\
\hline 50W downlight II & $\begin{array}{l}35 \mathrm{~W} \text { new lamp ECG type1 } \\
35 \mathrm{~W} \text { new lamp ECG type } 2 \\
35 \mathrm{~W} \text { new lamp ECG type3 }\end{array}$ & & $\begin{array}{l}1.2587 \\
1.2286 \\
1.2398\end{array}$ & $\begin{array}{l}0.9643 \\
0.9765 \\
0.9722\end{array}$ \\
\hline $18 \mathrm{~W}$ recessed fitting I & $\begin{array}{l}18 \mathrm{~W} \text { retrofitting ECG type } 1 \\
18 \mathrm{~W} \text { retrofitting ECG type } 2 \\
18 \mathrm{~W} \text { retrofitting ECG type } 3\end{array}$ & & $\begin{array}{l}1.2732 \\
1.3403 \\
1.3179\end{array}$ & $\begin{array}{l}0.9579 \\
0.9245 \\
0.9361\end{array}$ \\
\hline $54 \mathrm{~W}$ recessed fitting II & $\begin{array}{l}36 \mathrm{~W} \text { triphosphor tubes type } 1 \\
36 \mathrm{~W} \text { triphosphor tubes type } 2 \\
36 \mathrm{~W} \text { triphosphor tubes type } 3 \\
36 \mathrm{~W} \text { triphosphor tubes type } 4 \\
36 \mathrm{~W} \text { triphosphor tubes type } 5\end{array}$ & & $\begin{array}{l}1.2658 \\
1.2811 \\
1.2732 \\
1.3078 \\
1.2732\end{array}$ & $\begin{array}{l}0.9612 \\
0.9542 \\
0.9579 \\
0.9412 \\
0.9579\end{array}$ \\
\hline Old chillers & $\begin{array}{l}\text { New chillers type } 1 \\
\text { New chillers type } 2\end{array}$ & $\begin{array}{c}0.5 \\
0.4444\end{array}$ & & \\
\hline Electric geyser & $\begin{array}{l}3 \mathrm{~kW} \text { heat-pumps type } 1 \\
3 \mathrm{~kW} \text { heat-pumps type } 2 \\
3 \mathrm{~kW} \text { heat-pumps type } 3\end{array}$ & $\begin{array}{c}0.5 \\
0.4444 \\
0.5455\end{array}$ & & \\
\hline Electric geyser & $\begin{array}{l}22 \mathrm{~kW} \text { heat-pumps type } 1 \\
22 \mathrm{~kW} \text { heat-pumps type } 2 \\
22 \mathrm{~kW} \text { heat-pumps type } 3\end{array}$ & $\begin{array}{c}0.5 \\
0.5217 \\
0.4444\end{array}$ & & \\
\hline Electric geyser & $\begin{array}{l}9 \mathrm{~kW} \text { heat-pumps type } 1 \\
9 \mathrm{~kW} \text { heat-pumps type } 2 \\
9 \mathrm{~kW} \text { heat-pumps type } 3\end{array}$ & $\begin{array}{c}0.5 \\
0.4615 \\
0.4615\end{array}$ & & \\
\hline High-flow showerheads & $\begin{array}{l}\text { Low-flow showerheads type } 1 \\
\text { Low-flow showerheads type } 2\end{array}$ & & $\begin{array}{l}1.1568 \\
1.176\end{array}$ & $\begin{array}{l}0.9956 \\
0.992\end{array}$ \\
\hline No heater wraps & $\begin{array}{l}\text { Heater wraps type } 1 \\
\text { Heater wraps type } 2 \\
\text { Heater wraps type } 3\end{array}$ & $\begin{array}{l}0.2353 \\
0.25 \\
0.2\end{array}$ & & \\
\hline No thermal traps & $\begin{array}{l}\text { Thermal traps type } 1 \\
\text { Thermal traps type } 2\end{array}$ & $\begin{array}{l}0.1791 \\
0.2449\end{array}$ & & \\
\hline
\end{tabular}

management project, as described in equation (19):

$$
u_{i}^{j}(t)=\left\{\begin{array}{clrl}
0, & t & =1,3,5 \ldots \\
x_{i}^{j}-x_{i}^{j}(t), & & t=2,4,6 \ldots
\end{array}\right.
$$

which means maintenances take place at the end of the year 2,4,6... During each maintenance, all the failed items are fixed, so that the population size is increased to $x_{i}^{j}$. For the 8 scenarios, $\lambda_{1}=0.5, \lambda_{2}=0.6, \lambda_{3}=$ 0.2

\subsection{Illustrative results and analysis}

Fig. 1 illustrates how the fitness values converge to optimal during the optimization in Scenarios AD. Rapid convergence can be observed in curves corresponding to scenarios $B, C, D$. Within 100 steps, the curves become flat and the fitness values slowly descend to the optimal value. The solid curve which corresponds to scenario $A$ demonstrates several sharp descents, revealing the ability of escaping from local plateau. As introduced in the previous section, it is difficult to determine whether the final result is globally optimal. In the present model, DE is trusted to be able to obtain a good enough solution when sufficient iteration number is reached. The following table shows the performances can be achieved by DE.

Table 6 illustrates the corresponding performances after applying the optimal solutions. In Table 6, Energy Saving, Overall Profit and Overall Investment are the performance characteristics within the evaluation period. Percentage saved is the proportion of energy saving compared to the overall energy baseline. Initial Investment is the total cost of all units at the initial stage. The characteristics in Table 6 show how good the performances are with the obtained solution: all constraints are satisfied and performances are actually 
Table 5: Eight scenarios with different budgets and expected payback period

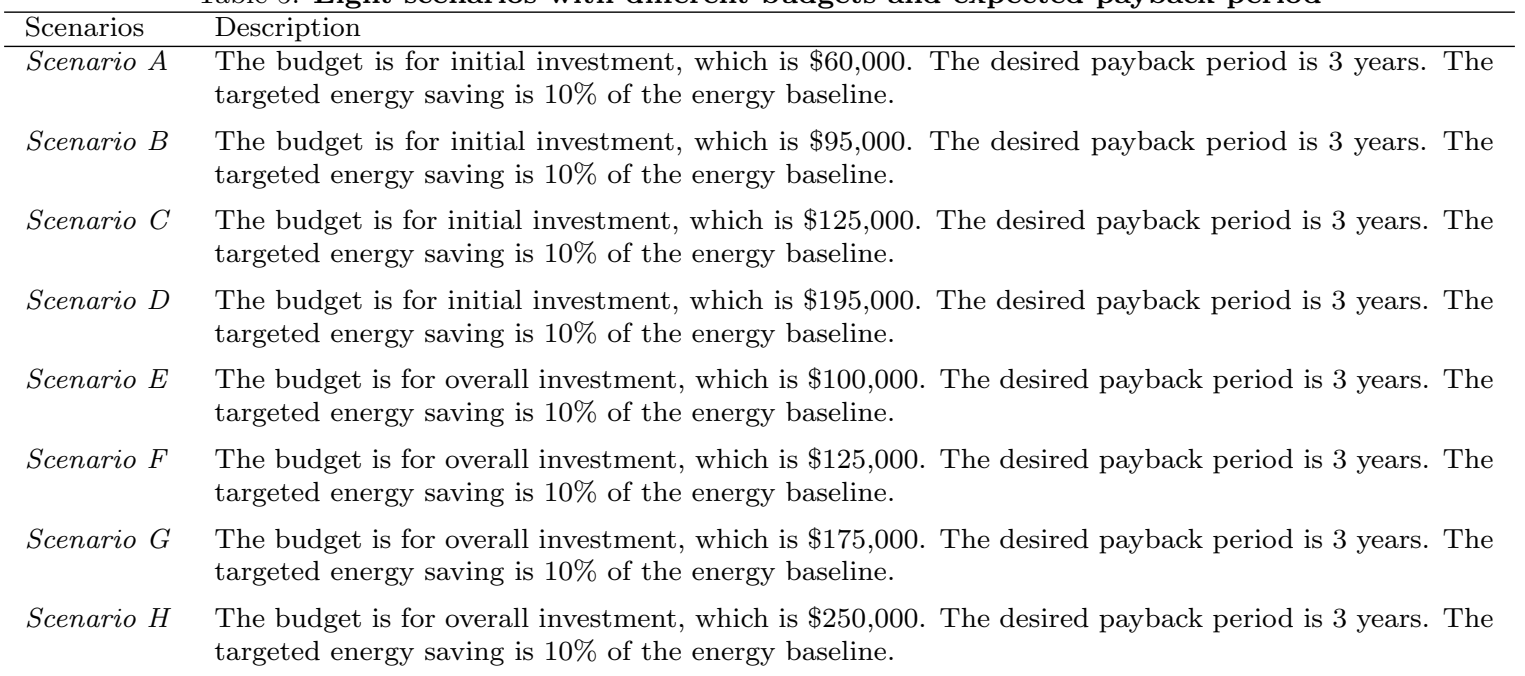
targeted energy saving is $10 \%$ of the energy baseline.

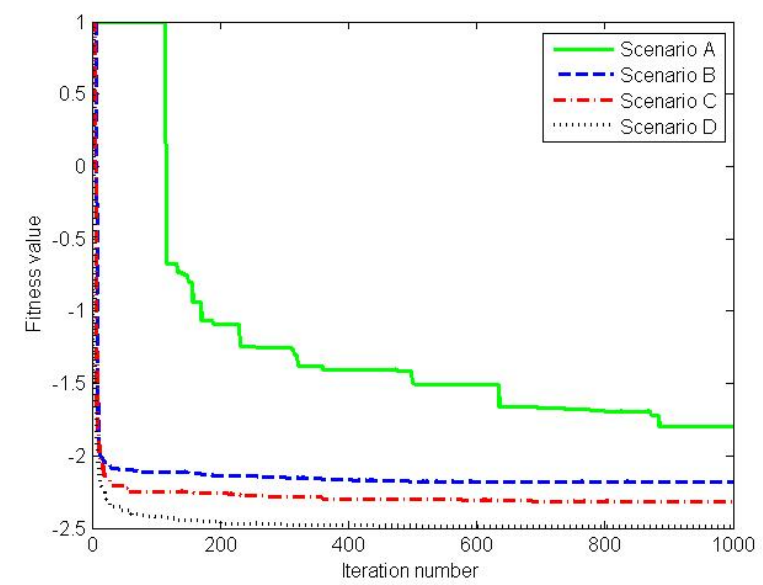

Figure 1: Convergence of the fitness values by DE during optimization: Scenarios A-D 
Table 6: Performances of the optimal solutions

\begin{tabular}{|c|c|c|c|c|c|c|c|}
\hline & \multirow{2}{*}{$\begin{array}{l}\text { Payback Period } \\
\text { (Month) }\end{array}$} & \multirow{2}{*}{$\begin{array}{c}\text { Energy Savings } \\
(\mathrm{kWh})\end{array}$} & \multirow{2}{*}{$\begin{array}{c}\text { Percentage } \\
\text { Saved }\end{array}$} & \multicolumn{2}{|c|}{ Investment $(\$)$} & \multirow{2}{*}{$\begin{array}{c}\text { Overall } \\
\text { Profit }(\$)\end{array}$} & \multirow[t]{2}{*}{$\operatorname{NPV}(\$)$} \\
\hline & & & & Initial & Overall & & \\
\hline Scenario $A$ & 13 & 6254370 & $10.65 \%$ & 59999.08 & 74664.88 & 713406.6 & 446561.8 \\
\hline Scenario $B$ & 19 & 7948240 & $13.54 \%$ & 94980.91 & 117119.7 & 782204.7 & 475804.9 \\
\hline Scenario $C$ & 23 & 9190815 & $15.65 \%$ & 124981.3 & 154418.7 & 840633.7 & 499910.4 \\
\hline Scenario $D$ & 33 & 13867120 & $23.62 \%$ & 194931.3 & 238434.4 & 860362.9 & 480573.4 \\
\hline Scenario E & 17 & 7393115 & $12.59 \%$ & 81628.21 & 99992.71 & 756256.7 & 465459.4 \\
\hline Scenario $F$ & 20 & 8191315 & $13.95 \%$ & 102015 & 124999.4 & 793474.5 & 480421.2 \\
\hline Scenario $G$ & 25 & 9874125 & $16.82 \%$ & 141727.6 & 174976.3 & 872425.8 & 512987 \\
\hline Scenario $H$ & 34 & 14537235 & $24.76 \%$ & 204326.9 & 249774.8 & 863053.6 & 478002.8 \\
\hline
\end{tabular}

Table 7: Performance of optimization results with old model

\begin{tabular}{|c|c|c|c|c|c|c|c|}
\hline & \multirow{2}{*}{$\begin{array}{c}\text { Payback Period } \\
\text { (Month) }\end{array}$} & \multirow{2}{*}{$\begin{array}{c}\text { Energy Savings } \\
(\mathrm{kWh})\end{array}$} & \multirow{2}{*}{$\begin{array}{c}\text { Percentage } \\
\text { Saved }\end{array}$} & \multicolumn{2}{|c|}{ Investment $(\$)$} & \multirow{2}{*}{$\begin{array}{c}\text { Overall } \\
\text { Profit }(\$)\end{array}$} & \multirow[t]{2}{*}{$\operatorname{NPV}(\$)$} \\
\hline & & & & Initial & Overall & & \\
\hline Scenario $A^{\prime}$ & 15 & 5242835 & $8.93 \%$ & 58136.98 & 125028.4 & 470462 & 228283.1 \\
\hline Scenario $B^{\prime}$ & 32 & 6262350 & $10.67 \%$ & 94983.9 & 214335.1 & 466440.1 & 153620.3 \\
\hline Scenario $C^{\prime}$ & 31 & 8762920 & $14.93 \%$ & 124459.6 & 242483.8 & 586299 & 209378.4 \\
\hline Scenario $D^{\prime}$ & 51 & 12136310 & $20.67 \%$ & 190469.6 & 374205.2 & 682995.2 & 167563.2 \\
\hline
\end{tabular}

much better than the target values implied in the constraints. The energy savings are significant comparing to the energy baseline, and the payback periods are shorter than 3 years, especially in scenarios A-C. In scenario D, the payback period is close to 3 years. This reveals the influence of various budgets: on the one hand, with growing budgets, the energy saving and the profit keep increasing; on the other hand, the payback periods are not actually improving as budgets grow.

In Table 6 , scenarios $A, B, C, D$ are cases where the budget is decided for the initial investment only, while in scenarios $E, F, G, H$ the budget is decided according to the total expenditure during the evaluation period. The results of each pair are similar; one can choose either method according to practical requirements. However, if one needs to control the expenditure on maintenance, the use of the constraint in equation (5) is recommended. In all 8 scenarios, the investment is very close to its budget. This implies that the DE algorithm generally gives priority to the most cost-effective alternative interventions according to the fitness function. With increased budget, the optimal solution comprises more items which are less cost-effective than the prior selected ones. Therefore the growth of the overall profit is not as significant as the investment. Such tendency illustrates the method's preference for cost-effective solutions. The radar charts in Figs. 2-3 demonstrate the shapes of the performance corresponding to the 8 scenarios. In order to show clearer results, the scales of the values of each performance characteristics are normalized to the similar range. It can be observed that the shapes of the optimal performances in the radar charts are very similar, only the scales are different. The charts reveal the effectiveness of the optimization method to find global optimal solutions.

The existing optimization model in [12] considers only one preselected retrofitting measure for each facility type. The SPP method is adopted in [12] without taking LCCA into account. Table 7 illustrates the performances of the optimal solutions obtained from the model in [12]. According to this model, the initial investment is the overall cost of the project, thus only scenarios $A^{\prime}, B^{\prime}, C^{\prime}, D^{\prime}$ are tested, where the conditions are same with scenarios A-D, respectively. The same criteria as proposed in the present model are adopted to characterize the performances. Fig. 4 shows the shape of the performances with the old model. From Table 7 and Fig. 4, with the old model, higher investments are corresponding with lower savings and profits, reveal worse efficiency than the present model. As failures of items and the maintenances are inevitable during the lifetime of the project and the building, the old model cannot provide the most cost-effective solution, some of the solutions are not even feasible according to the constraints. Our model is proved to be a better method for planning a practical retrofitting project. 


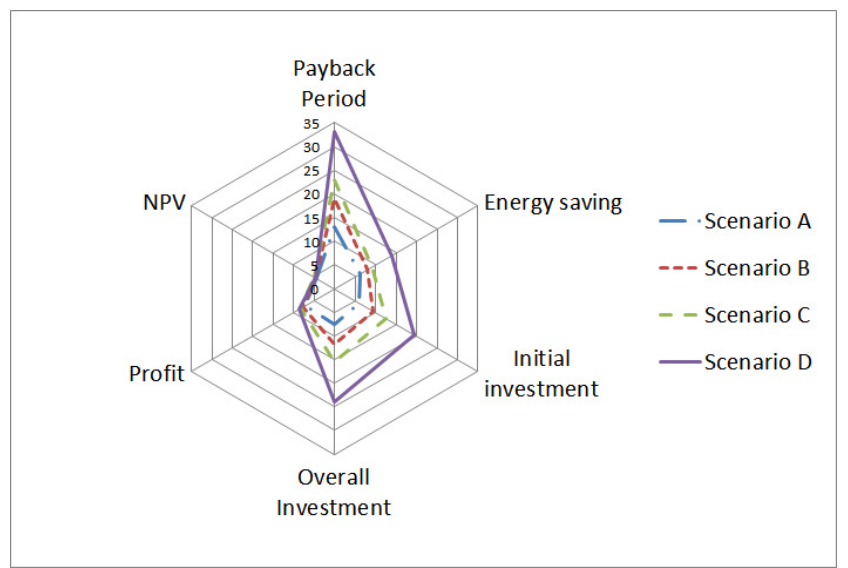

Figure 2: Performances in Scenarios A-D

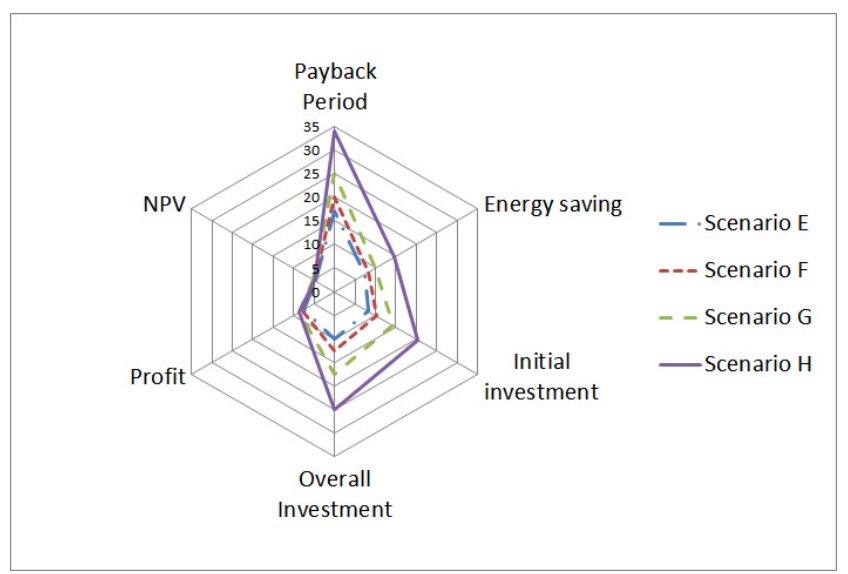

Figure 3: Performances in Scenarios E-H

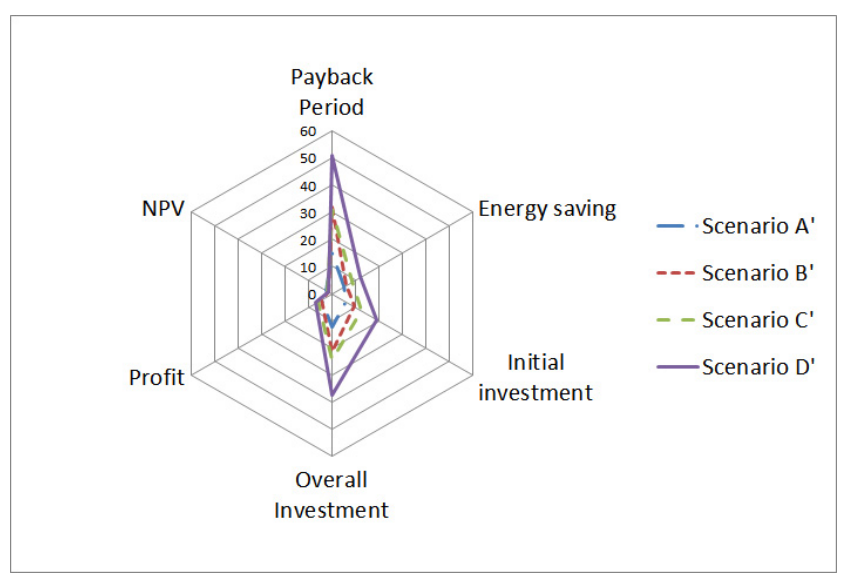

Figure 4: Performances with the old model 


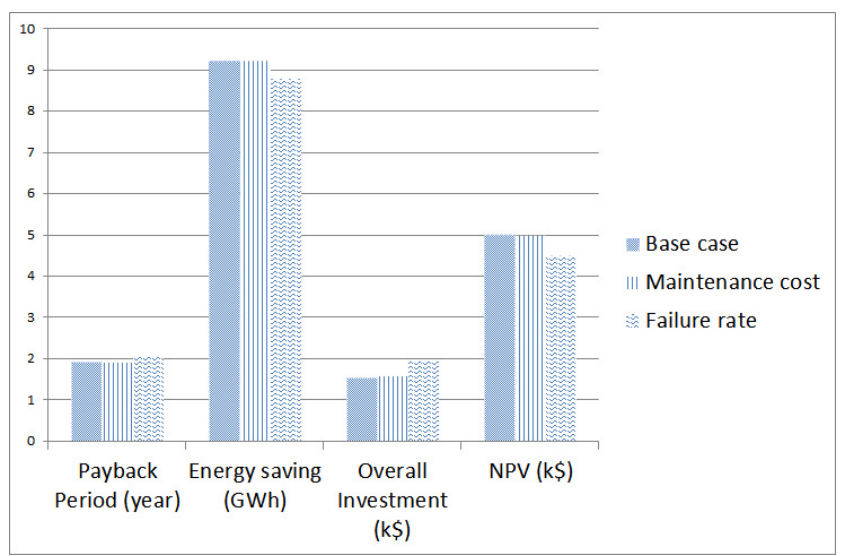

Figure 5: Sensitivity analysis of the influence of maintenance cost and failure rate

\subsection{Sensitivity analysis}

In practise, many of the parameters required by the optimization model are not know with $100 \%$ confidence and have to be estimated, such as the average energy savings, the electricity price, the discount and interest rate and the failure rate of the interventions. The uncertainties of the parameters can influence the actual performance of the project. In [12], a set of sensitivity analysis of several external influences, such as the auditing error, electricity prices, wrongly specified energy savings and initial investment cost are given. In our present model, the influences of the uncertainties of maintenance cost and the failure rate must be considered as well. Scenario C is considered for illustration of such influences on payback period, energy savings, overall investment cost and NPV. The results are given in Fig. 5.

The maintenance cost of the interventions can increase due to the fluctuation in economy. Significant uncertainty of the failure rates of the interventions is inevitable in practise. As a result, the influence of such bias on the performance of the optimal solution must be checked. Fig. 5 shows the influence when the maintenance costs and the failure rates of all interventions are increased by $10 \%$. According to the Fig. 5, the influence of the increase of maintenance costs is not as significant as the uncertainties of the failure rates. When failure rate is increased, the payback period becomes 25 months and the energy saving becomes $8770500 \mathrm{kWh}$. The overall investment increases to $\$ 193735.4$ and the NPV decreases to $\$ 447789.6$.

\section{Conclusion and future work}

This paper presents an optimization model for building retrofitting planning. While maximizing the energy savings and the economic benefits of the project as proposed in the existing research [12], the present model introduces a building investment analysis method associated with life-cycle cost analysis. The new method takes maintenance costs of retrofitted items into account to evaluate the overall cost-effectiveness of the solution within a specific time frame. Furthermore, more available retrofitting options in a building retrofitting project are introduced. A range of possible alternative measures as well as the quantities of retrofitted facilities using the selected measures are evaluated. Considering a combination of alternative measures allows the best cost-effectiveness of a retrofitting plan under the budget limit. The illustrative results and analysis show that with the present model, it is possible to find the most cost-effective long-term solution that includes life-cycle cost analysis and multiple option of retrofitting measures, unlike the existing studies that exclude these. A DE algorithm, as verified in the case study to be able to find the optimal solution for a building retrofitting problem, is adopted to solve the proposed optimization problem.

There are several topics which call for further studies on the investigated topic: a power saving profile can be more informative than the annual energy saving estimation; the impact of the retrofitting project, e.g., 
the influence on occupants' behaviors has not yet been investigated; more criteria, such as the comfort requirements can be introduced in the future optimization model.

\section{References}

[1] H. Khatib, IEA world energy outlook 2011: A comment, Energy Policy (2012).

[2] Z. Ma, P. Cooper, D. Daly, L. Ledo, Existing building retrofits: Methodology and state-of-the-art, Energy and Buildings (2012).

[3] J. S. Gero, N. D'Cruz, A. D. Radford, Energy in context: A multicriteria model for building design, Building and Environment 18 (1983) 99-107.

[4] F. Flourentzou, C.-A. Roulet, Elaboration of retrofit scenarios, Energy and Buildings 34 (2002) 185-192.

[5] M. Jaggs, J. Palmer, Energy performance indoor environmental quality retrofit: A european diagnosis and decision making method for building refurbishment, Energy and Buildings 31 (2000) 97-101.

[6] E. Rey, Office building retrofitting strategies: Multicriteria approach of an architectural and technical issue, Energy and Buildings 36 (2004) 367-372.

[7] P. Blondeau, M. Spérandio, F. Allard, Multicriteria analysis of ventilation in summer period, Building and Environment 37 (2002) $165-176$

[8] Z. Chen, D. Clements-Croome, J. Hong, H. Li, Q. Xu, A multicriteria lifespan energy efficiency approach to intelligent building assessment, Energy and Buildings 38 (2006) 393-409.

[9] E. Asadi, M. G. da Silva, C. H. Antunes, L. Dias, Multi-objective optimization for building retrofit strategies: A model and an application, Energy and Buildings 44 (2012) 81-87.

[10] C. Diakaki, E. Grigoroudis, D. Kolokotsa, Towards a multi-objective optimization approach for improving energy efficiency in buildings, Energy and Buildings 40 (2008) 1747-1754.

[11] R. Evins, A review of computational optimisation methods applied to sustainable building design, Renewable and Sustainable Energy Reviews 22 (2013) 230-245.

[12] E. M. Malatji, J. Zhang, X. Xia, A multiple objective optimisation model for building energy efficiency investment decision, Energy and Buildings 61 (2013) 81-87.

[13] O. Kaynakli, A review of the economical and optimum thermal insulation thickness for building applications, Renewable and Sustainable Energy Reviews 16 (2012) 415-425.

[14] C. C. Menassa, Evaluating sustainable retrofits in existing buildings under uncertainty, Energy and Buildings 43 (2011) $3576-3583$.

[15] F. Kreith, D. Y. Goswami, Energy Management and Conservation Handbook, CRC Press, 2007.

[16] M. Krarti, Energy Audit of Building Systems: An Engineering Approach, Second Edition, CRC Press, 2011.

[17] D. S. Remer, A. P. Nieto, A compendium and comparison of 25 project evaluation techniques. part 1: Net present value and rate of return methods, International Journal of Production Economics 42 (1995) 79-96.

[18] G. Verbeeck, H. Hens, Energy savings in retrofitted dwellings: Economically viable, Energy and Buildings 37 (2005) $747-754$.

[19] S. Petersen, S. Svendsen, Method for component-based economical optimisation for use in design of new low-energy buildings, Renewable Energy 38 (2012) 173-180.

[20] Y. K. Juan, J. H. Kim, K. Roper, D. Castro-Lacouture, GA-based decision support system for housing condition assessment and refurbishment strategies, Automation in Construction 18 (2009) 394-401.

[21] R. Storn, K. Price, Differential evolution: A simple and efficient heuristic for global optimization over continuous spaces, Journal of Global Optimization 11 (1997) 341-359.

[22] J. Vesterstrom, R. Thomsen, A comparative study of differential evolution, particle swarm optimization, and evolutionary algorithms on numerical benchmark problems, in: Evolutionary Computation, 2004. CEC2004. Congress on, volume 2, IEEE, 2004, pp. 1980-1987.

[23] H. Carstens, X. Xia, J. Zhang, X. Ye, Characterising compact fluorescent lamp population decay, in: 11th IEEE AFRICON Conference in Africa, Mauritius, 2013.

[24] P. O'Connor, A. Kleyner, Practical Reliability Engineering, Wiley, 2011.

[25] H. Ong, T. Mahlia, H. Masjuki, D. Honnery, Life cycle cost and sensitivity analysis of palm biodiesel production, Fuel 98 (2012) 131-139.

[26] R. T. Marler, J. S. Arora, The weighted sum method for multi-objective optimization: new insights, Structural and Multidisciplinary Optimization 41 (2010) 853-862.

[27] A. K. Qin, V. L. Huang, P. N. Suganthan, Differential evolution algorithm with strategy adaptation for global numerical optimization, IEEE Transactions on Evolutionary Computation 13 (2009) 398-417.

[28] J. Zhang, A. C. Sanderson, Jade: adaptive differential evolution with optional external archive, IEEE Transactions on Evolutionary Computation 13 (2009) 945-958. 